\title{
Biomechanical characteristics of Taekwondo athletes: kicks and punches vs. laboratory tests
}

\author{
Krzysztof Buśko ${ }^{1}$, Pantelis T. Nikolaidis² \\ ${ }^{1}$ Department of Anatomy and Biomechanics, Kazimierz Wielki University, Bydgoszcz, Poland; ${ }^{2}$ Department of Physical \\ and Cultural Education, Hellenic Army Academy, Athens, Greece
}

\section{Summary}

Study aim: The aim of the study was to examine biomechanical characteristics of taekwondo athletes comparing kicks and punches with laboratory tests of muscle strength and power.

Material and methods: Six male taekwondo athletes participated in this study. Measurements of maximal punching with the rear hand (hook and straight punches) and kicking (Apdolio and Dwit Chagi) force were performed on a boxing dynamometer. Also, the following laboratory tests were performed: jump height and power output in counter movement jump (CMJ) and spike jump (SPJ), muscle strength for 10 muscle groups and force-velocity $(F-v)$ relationship.

Results: Mean maximal straight and hook punching forces were $1659.2 \pm 254.2 \mathrm{~N}$ and $1843.8 \pm 453.3 \mathrm{~N}$, respectively. Maximal Apdolio rear leg, Apdolio lead leg and Dwit Chagi rear leg kicking forces were $3541.3 \pm 1130.3 \mathrm{~N}, 3205.3 \pm 965.1 \mathrm{~N}$ and $3568.0 \pm 1306.0 \mathrm{~N}$, respectively. The heights of jumps were $0.501 \pm 0.040 \mathrm{~m}$ (CMJ) and $0.554 \pm 0.034 \mathrm{~m}$ (SPJ). A strong correlation between the maximal force of a punch and maximal joint torques was observed.

Conclusions: The values of kicking forces developed in a simulated fight were lower than the forces developed in the test of individual kicks. Strong relationships were observed between leg power developed in the SPJ and force of individual Apdolio kicks performed with the lead $(r=0.87, p<0.05)$ and rear leg $(r=0.74)$. Based on these findings, it was concluded that maximal joint torques and height of the SPJ could be used as a proxy of kicking force.

Key words: Apdolio - Dwit Chagi - Jump - Power - Force

\section{Introduction}

Taekwondo is a Korean martial art, characterized by fast, high and spinning kicks. In combat sports, tournament results are determined by a number of interrelated factors: anthropometrics, motor characteristics, technique, tactics, psychological traits of the athlete, and the refereeing method $[10,25]$. Training in taekwondo, which consists mainly of kata techniques and sparring, includes fist blows, kicks, blocks and hits executed while standing or during body movements. Thus, taekwondo training might be expected to improve both aerobic and anaerobic capacity, as well as power output at high velocities and low loads. These factors affect the $F-v$ curves determined for taekwondo athletes. Introduced in 2009, the new computer system for judging taekwondo should change the way of fighting and training methods [8]. In taekwondo, many studies have examined somatic characteristics [6], personality types [28], and sports injuries [17], and evaluated physiological parameters $[9,20]$. A few comprehensive studies have previously examined the biomechanical characteristics of taekwondo athletes [22, 23]. Therefore, the evaluation of punching force, strength, power and jumping abilities is fundamental in taekwondo performance. Punching and kicking force is rarely measured in athletes. A few studies have documented the relationships between punching force and power output or joint torque in boxers [16], but not in taekwondo athletes. There were not found studies that compared punching or kicking force with rear and lead limbs in taekwondo athletes. Furthermore, few studies have described the relationship between the force of the blow and maximum torques or muscle forces in selected muscle groups [16]. The application of a system to measure the force of punches and kicks to control the effects of training and to evaluate the relationships between the force of the blow and kicks and selected physical characteristics would enhance our understanding of taekwondo biomechanics. Accurate knowledge 
of the current level of muscle strength is important for the functional assessment of professional potential. Therefore, the aim of the present study was to examine biomechanical characteristics of taekwondo athletes comparing kicks and punches with laboratory tests of muscle strength and power.

\section{Material and methods}

Six male national and elite taekwondo (World Taekwondo Federation, WTF) athletes (age $17.7 \pm 0.7$ years, body height $179.5 \pm 4.1 \mathrm{~cm}$, body mass $62.3 \pm 6.0 \mathrm{~kg}$, training experience of $6.5 \pm 1.6$ years) participated in this study. Ethical approval for this study was provided by the Local Ethical Committee at the Institute of Sport - National Research Institute, Warsaw, Poland and the Senate Research Ethics Committee of the Józef Piłsudski University of Physical Education in Warsaw, Poland. Written informed consent was obtained from participants or their parents if a participant was under 18 years of age. The study was conducted in accordance with the Declaration of Helsinki.

All measurements were performed after the standard warm-up in the Laboratory of Biomechanics in the following order: jump on the force plate, muscle strength, force of punches and kicks, F-v relationship.

\section{Power output and jump height}

The power output of lower extremities and the height of rise of the body's centre of mass (COM) during vertical jumps were measured using the Kistler force plate Type 9281 A (Kistler Instrumente AG Winterthur, Switzerland) with the Kistler amplifier Type 9865 B 1 Y28 (Kistler Instrumente AG Winterthur Switzerland). The amplifier was connected to a computer via an A/D converter. The MVJ software package ("JBA" Zb. Staniak, Poland) was used for measurements. In the physical model used in the study, the participant's body mass bouncing on the force plate was reduced to a particle affected by the vertical components of external forces: the body's gravity force and the vertical component of the platform's reaction force. Peak power $\left(\mathrm{P}_{\max }[\mathrm{W}]\right)$, relative peak power $\left(\mathrm{P}_{\max } \cdot \operatorname{mass}^{-1}\left[\mathrm{~W} \cdot \mathrm{kg}^{-1}\right]\right)$ and maximal height (h $[\mathrm{m}])$ of rise of the body's COM were calculated from the recorded ground reaction force of the platform [12].

Each participant performed six vertical jumps on the force plate: three counter-movement jumps (CMJs) and three spike jumps (SPJs). The characteristics of each jumping test were as follows:

- $\mathrm{CMJ}$ - a vertical jump from a standing erect position, preceded by an arm-swing and counter-movement of the body COM before the take-off;

- SPJ - a vertical jump performed with a 3-4 step run-up before the take-off.
The participants were told to jump as high as possible in each trial. There were $5 \mathrm{~s}$ breaks between the CMJs and 1 min breaks between the SPJs. The jump with the highest elevation of the body's COM was chosen for statistical analysis.

The maximum error of the measurement channel is less than $0.5 \%$. The total error in the measurement of the peak power output and maximal height of rise of the body COM did not exceed $3.3 \%$ and $4.5 \%$, respectively. The maximal error of repeatability, expressed by the coefficient of variability, was $3.0 \%$ for maximal height of rise of the body COM and $3.4 \%$ for peak power output.

\section{Muscle strength (peak joint torque)}

The peak joint torque (JT) of the flexors and extensors of the elbow, shoulder, hip, knee and trunk was measured under static conditions using a special torque meter (Institute of Sport, Poland) type SMS1 (upper extremities) and SMS2 (lower extremities and trunk) [11]. During the measurements of the elbow flexors and extensors, the participant was in a sitting position, with his or her arm and forearm positioned at a $90^{\circ}$ angle and placed on the armrest, and with the trunk stabilized. The joint torque of the shoulder flexors and extensors was also measured in a sitting position. The flexion angle was set at $70^{\circ}$ and the extension angle was $50^{\circ}$. The trunk was stabilized with the chest pressed against the backrest. The measurements of the knee flexors and extensors were carried out in a sitting position. The hip and knee joints were bent at $90^{\circ}$. The study participants were stabilized at the level of the anterior superior iliac spines and thighs, with the upper extremities resting on the chest. The participants were lying face down during the measurements of the hip extensors, and face up during the measurement of the hip flexors. The hip joint angle was $90^{\circ}$ during both measurements. The maximal extension of the elbow, knee and hip joints was accepted as $0^{\circ}$. For the shoulder joint, the position of the arm along the side was taken as $0^{\circ}$. The axis of rotation during joint torque measurements corresponded to the axis of rotation of the torque meter. Joint torques of the right and left limb were measured separately, with flexion followed each time by extension. The participants were instructed to develop maximal possible contraction.

The total error in the measurement of the maximal joint torque did not exceed $4 \%$. The maximal error of repeatability, expressed by the coefficient of variability, was $4.2 \%$, while for the individual muscle groups it was $1.8 \%$ and $2.1 \%$ for the knee and hip extensors respectively, $4.9 \%$ for the hip flexors, and $6.3 \%$ for the shoulder extensors.

\section{Force-velocity and power-velocity relationships}

The force-velocity $(F-v)$ and power-velocity $(P-v)$ relationships were determined on the basis of the results recorded from a Monark 874 E cycle ergometer (Sweden) 
connected to a PC, using the MCE 4.0 software package ("JBA" Zb. Staniak, Poland). After adjustment of the ergometer saddle and handlebars, each participant performed the tests in a stationary position, without lifting body off the saddle and with feet strapped onto the pedals. Each participant performed five 10-second maximal cycle ergometer tests with an increasing external load equalling $2.5,5.0,7.5,10.0$ and $12.5 \%$ of body weight (BW), respectively. Two-minute rests were used between the tests. The standard procedure for performing the exercises was followed, and the participants were verbally encouraged to achieve and maintain the maximal pedalling rate as quickly as possible. Using MCE, the maximal power output at a given load $\left(P_{\mathrm{i}} ; i-\right.$ load value $)$ and the velocity $\left(v_{\mathrm{i}}\right)$ to achieve $P_{\mathrm{i}}$ were determined [18].

The total error of the measurement of power output in tests with increasing external loads of 2.5, 5.0, 7.5, 10.0 and $12.5 \% \mathrm{BW}$ ranged from 1.1 to $1.8 \%$.

\section{Punching bag with in-built strain gauge}

The measurements of the punch force were conducted at the Institute of Sport using a versatile Boxing Training Simulator (BTS). The BTS-3 version of the simulator is equipped with a dynamometric punching bag with an in-built strain gauge (for details see [1]). The cylindrical punching surface (L) is $0.5 \mathrm{~m}$, and the outer diameter (D) is $0.48 \mathrm{~m}$. The bag is suspended on a set of stabilizing ropes. Two signal diodes designed for guiding the sequence of strikes are mounted on an upper cylindrical section of the punching bag. The dynamometric punching bag is connected with an external integrated strain gauge amplifier equipped with strain gauge bridge power supply sub-assemblies, signal conditioning sub-assemblies, an analogue-to-digital converter, and a USB interface to connect with a computer. The system is controlled by the BTS specialist software ("JBA" Zb. Staniak, Poland). The punching bag measures the resultant reaction force in the plane perpendicular to the cylindrical surface of the punching bag as well as the direction of the force applied during a single punch or kick and the force of consecutive strikes. The punching bag also offers the possibility for a simulated boxing match. When measuring punching and kicking force with the punching bag, the taekwondo athletes:

- threw a series of three single straight punches and hooks with the rear hand to develop maximal punching force (MPF),

- delivered three Apdolio kicks with the lead leg and rear leg kicks to develop maximal kick force (MKF),

- delivered Apdolio kicks (roundhouse kick: it is applied to attack the opponent, for defence against an opponent or to counter-attack the opponent) with the lead leg and rear leg, and Dwit Chagi kicks (back kick: the practitioner turns the body away from the target and pushes the back leg straight toward the target, hitting it with the heel while watching over the shoulder) with the rear leg to develop maximal kick force during simulation of a 120 s fight (SF120).

The total error in the measurement of the force and time was $0.46 \%$ and $1.0 \%$, respectively [1].

\section{Warm-up}

Before vertical jump testing, joint torque measurement and measurements of strike force, the participants performed a 5-minute warm-up consisting of light exercise (i.e., running, circulation of the arms, hips and trunk, squats followed by stretching exercises). Before evaluation of the force-velocity relationship, the participants performed a 2-minute submaximal warm-up on a cycle ergometer (Monark 874 E, Sweden). They were instructed to cycle at $50-60 \mathrm{rpm}$ and to maintain a power output of approximately $150 \mathrm{~W}$.

\section{Statistical analysis}

A repeated measures analysis of variance (ANOVA) was used to compare the study results between the rear limb and lead limb. The significance of differences between means was evaluated post hoc with Tukey's test. The effect size (ES) in ANOVA was evaluated by eta square and interpreted as follows: $0.01 \leq \eta^{2}<0.06$ small, $0.06 \leq \eta^{2}<0.14$ medium and $\eta^{2} \geq 0.14$ large [7]. Pearson's correlation coefficient $r$ was used to evaluate correlations between all parameters. The thresholds used to qualitatively assess $r$ was based on Hopkins [14], using the following criteria: $<0.1$, trivial; $0.1-0.3$, small; $0.3-0.5$, moderate; $0.5-0.7$, large; $0.7-0.9$, very large; $>0.9$ nearly perfect. For the statistical analyses, the alpha $(\alpha)$ value was set at 0.05 . All computations were performed using the STATISTICA software (v. 10.0, StatSoft, USA).

\section{Results}

The results obtained for joint torques (JT) are presented in Table 1. Joint torques in the lead hand extensors of the shoulder joint were significantly higher than in the rear hand $\left(\mathrm{F}_{1,5}=10.71 ; \mathrm{P}=0.022 ; \eta^{2}=0.6818\right)$. The joint torque of the extensor of the shoulder of the lead limb was significantly higher than in the rear one. Table 2 presents mean values $( \pm \mathrm{SD})$ of maximal force $\left(\mathrm{F}_{\max }\right)$ of a straight punch and hook in the test of maximal punching force (MPF) for the rear hand, maximal force of an Apdolio kick with the rear and lead leg (MKF), maximal force of Apdolio kicks and Dwit Chagi kicks performed with the rear and lead leg (MKF), and maximal force of the Apdolio and Dwit Chagi kicks during a simulated 120 s fight (SF120) on a dynamometric punching bag for the lead and rear leg. The maximal force of the straight punch and hook with the rear hand did 
Table 1. Mean values $( \pm \mathrm{SD})$ of the joint torque $[\mathrm{N} \cdot \mathrm{m}]$ of the flexors (F) and extensors (E) of the elbow, shoulder, hip and knee joints, and the flexors and extensors of the trunk

\begin{tabular}{lccc}
\hline Variables & & Rear limb & Lead limb \\
\hline Elbow & F & $60.8 \pm 7.8$ & $57.3 \pm 12.5$ \\
{$[\mathrm{~N} \cdot \mathrm{m}]$} & E & $37.0 \pm 7.6$ & $36.7 \pm 4.6$ \\
\hline Shoulder & F & $40.0 \pm 9.4$ & $46.0 \pm 7.2$ \\
{$[\mathrm{~N} \cdot \mathrm{m}]$} & E & $54.2 \pm 8.5$ & $61.7 \pm 12.7 *$ \\
\hline $\mathrm{Hip}$ & F & $97.7 \pm 12.1$ & $92.3 \pm 9.1$ \\
{$[\mathrm{~N} \cdot \mathrm{m}]$} & E & $398.0 \pm 77.9$ & $392.5 \pm 79.5$ \\
\hline $\mathrm{Knee}$ & F & $113.5 \pm 22.2$ & $110.2 \pm 17.8$ \\
{$[\mathrm{~N} \cdot \mathrm{m}]$} & E & $260.3 \pm 67.2$ & $236.0 \pm 45.7$ \\
\hline Trunk & F & $157.3 \pm 23.2$ & \\
{$[\mathrm{~N} \cdot \mathrm{m}]$} & E & $389.3 \pm 89.6$ & \\
\hline
\end{tabular}

* - indicates statistically significant difference from the rear limb, $\mathrm{p}<0.05$.

not differ significantly. The force of the Apdolio kick with the rear leg was significantly higher than the force of the kick with the lead leg $\left(\mathrm{F}_{1,5}=60.18 ; \mathrm{P}<0.001 ; \eta^{2}=0.9233\right)$. The values of forces for the Apdolio kicks developed in the simulated fight on the punching bag (SF120) did not differ significantly between the rear and lead legs. Table 3 presents the results obtained during determination of the power-velocity relationship. Table 4 illustrates the results of the CMJ and SPJ.

The values of the Pearson's correlation coefficients between peak joint torques (JT) and force developed for punches and kicks during MPF, MKF and SF120 are presented in Tables 5 and 6 . The value of the straight punch force with the rear leg highly correlated with maximal joint torques except for the torques produced by the knee flexors and trunk flexors. In the case of Apdolio kicks, a high correlation was found between the maximal force of kicks and maximal torques in both upper limbs and the hip extensors and flexors. In the case of the force developed during kicking in the simulated fight test, a high correlation with joint torques in the hip flexors and extensors, knee extensors and trunk extensors was observed for the Apdolio kicks with the lead leg. Furthermore, a negative correlation between the force of the kick and peak joint torques was observed for the rear leg for knee extensors, hip extensors and trunk flexors and extensors. In the case of the Dwit Chagi kicks, the force was negatively correlated with JT in the trunk flexors and extensors and hip extensors. No significant correlations were found between the force of punches and kicks and power developed during

Table 2. Mean values ( \pm SD) for the maximal straight and hook punching forces (MPF), maximal kicking forces (MKF) of the Apdolio, and maximal kicking forces of the Apdolio and Dwit chagi during simulation of a 120 s fight (SF120) for lead and rear limbs in taekwondo athletes

\begin{tabular}{lcc}
\hline Variables & Rear limb & Lead limb \\
\hline MPF: straight punch [N] & $1659.2 \pm 254.2$ & \\
MPF: hook punch [N] & $1843.8 \pm 453.3$ & \\
SF120: Dwit chagi [N] & $3568.0 \pm 1306.0$ & \\
SF120: Apdolio [N] & $3541.3 \pm 1130.3$ & $3205.3 \pm 965.1$ \\
MKF: Apdolio [N] & $4580.8 \pm 641.1$ & $3409.5 \pm 581.3^{*}$ \\
\hline
\end{tabular}

* - indicates statistically significant difference from the rear limb, $\mathrm{p}<0.05$.

Table 3. Absolute $(P)$ and relative $\left(P \cdot\right.$ body mass $\left.^{-1}\right)$ power outputs recorded for the external force-velocity relationship (mean values $\pm \mathrm{SD})$

\begin{tabular}{lccc}
\hline Load [\% BW] & $P[\mathrm{~W}]$ & $P_{\max } \cdot$ body $\mathrm{mass}^{-1}\left[\mathrm{~W} \cdot \mathrm{kg}^{-1}\right]$ & $v[\mathrm{rpm}]$ \\
\hline 2.5 & $294.3 \pm 25.1$ & $4.73 \pm 0.25$ & $190.0 \pm 11.0$ \\
5.0 & $532.6 \pm 52.4$ & $8.56 \pm 0.51$ & $174.4 \pm 10.0$ \\
7.5 & $704.0 \pm 66.7$ & $11.32 \pm 0.73$ & $153.0 \pm 9.8$ \\
10.0 & $733.4 \pm 71.0$ & $11.83 \pm 1.34$ & $120.6 \pm 14.1$ \\
12.5 & $708.6 \pm 76.8$ & $11.51 \pm 2.09$ & $93.8 \pm 17.4$ \\
\hline $\max$ & $758.2 \pm 61.1$ & $12.25 \pm 1.51$ & $111.7 \pm 11.5$ \\
\hline
\end{tabular}


Table 4. Mean values $( \pm \mathrm{SD})$ of the height of rise of the body mass center $(h)$, peak power output $\left(P_{\text {max }}\right)$, relative peak power output $\left(P_{\max } \cdot\right.$ mass $\left.^{-1}\right)$ during counter-movement jumps (CMJ) and spike jumps (SPJ) on the force plate

\begin{tabular}{lccc}
\hline Jump & $P[\mathrm{~W}]$ & $P_{\max } \cdot \mathrm{mass}^{-1}\left[\mathrm{~W} \cdot \mathrm{kg}^{-1}\right]$ & $h[\mathrm{~m}]$ \\
\hline CMJ & $2440.5 \pm 731.7$ & $34.15 \pm 6.56$ & $0.501 \pm 0.040$ \\
SPJ & $3573.8 \pm 798.5$ & $56.31 \pm 10.56$ & $0.554 \pm 0.034$ \\
\hline
\end{tabular}

Table 5. The Pearson's linear correlation coefficients between the maximal straight hook punching forces [N], maximal kicking forces $[\mathrm{N}]$ of the Apdolio for lead and rear limb and joint torque $[\mathrm{N} \cdot \mathrm{m}]$ of the flexors $(\mathrm{F})$ and extensors $(\mathrm{E})$ of the rear limb for the elbow, shoulder, hip and knee joints and the flexors and extensors of the trunk

\begin{tabular}{lccccc}
\hline Variables & & Straight punch [N] & Hook punch [N] & Apdolio kick with lead leg [N] & Apdolio kick with rear leg [N] \\
\hline Elbow & F & $0.94^{*}$ & 0.37 & 0.73 & 0.73 \\
{$[\mathrm{~N} \cdot \mathrm{m}]$} & $\mathrm{E}$ & 0.64 & 0.56 & 0.71 & $0.83^{*}$ \\
\hline Shoulder & $\mathrm{F}$ & $0.88^{*}$ & 0.24 & 0.55 & 0.60 \\
{$[\mathrm{~N} \cdot \mathrm{m}]$} & $\mathrm{E}$ & 0.55 & 0.49 & $0.83^{*}$ & 0.49 \\
\hline Hip & $\mathrm{F}$ & 0 & -0.34 & -0.06 & -0.05 \\
{$[\mathrm{~N} \cdot \mathrm{m}]$} & $\mathrm{E}$ & 0.52 & 0.53 & 0.29 & 0.38 \\
\hline Knee & F & 0.64 & 0.34 & 0.66 & 0.77 \\
{$[\mathrm{~N} \cdot \mathrm{m}]$} & $\mathrm{E}$ & 0.77 & 0.45 & 0.62 & 0.45 \\
\hline Trunk & F & 0.16 & -0.17 & 0.10 & -0.30 \\
{$[\mathrm{~N} \cdot \mathrm{m}]$} & $\mathrm{E}$ & 0.74 & 0.22 & 0.36 & 0.28 \\
\hline
\end{tabular}

$*-\mathrm{p}<0.05$

Table 6. The Pearson's linear correlation coefficients between the maximal straight hook punching forces [N], maximal kicking forces $[\mathrm{N}]$ for theApdolio kick for lead and rear limb and joint torque $[\mathrm{N} \cdot \mathrm{m}]$ of the flexors $(\mathrm{F})$ and extensors $(\mathrm{E})$ of the lead limb for the elbow, shoulder, hip and knee joints

\begin{tabular}{lccccc}
\hline Variables & & Straight punch $[\mathrm{N}]$ & Hook punch [N] & Apdolio kick with lead leg $[\mathrm{N}]$ & Apdolio kick with rear leg $[\mathrm{N}]$ \\
\hline Elbow & F & $0.95^{*}$ & 0.45 & 0.51 & 0.71 \\
{$[\mathrm{~N} \cdot \mathrm{m}]$} & E & $0.82^{*}$ & -0.09 & 0.18 & 0.51 \\
\hline Shoulder & F & 0.60 & -0.36 & -0.01 & 0.33 \\
{$[\mathrm{~N} \cdot \mathrm{m}]$} & E & 0.71 & 0.45 & 0.78 & 0.57 \\
\hline Hip & F & 0.18 & -0.59 & -0.22 & -0.03 \\
{$[\mathrm{~N} \cdot \mathrm{m}]$} & E & 0.27 & 0.46 & 0.11 & 0.34 \\
\hline Knee & F & 0.41 & 0.48 & 0.74 & 0.71 \\
{$[\mathrm{~N} \cdot \mathrm{m}]$} & E & 0.76 & 0.27 & 0.54 & 0.39 \\
\hline
\end{tabular}

$*-\mathrm{p}<0.05$

determination of the $F-v$ profiles. Strong relationships were observed between leg power developed in the SPJ and force of individual Apdolio kicks (MKF) performed with the lead $(r=0.87, p<0.05)$ and rear leg $(r=0.74)$. No correlation was found between the parameters of the CMJ and force of the Apdolio kicks.

\section{Discussion}

The aim of the study was to investigate the biomechanical factors affecting success in taekwondo. The study analysed peak joint torques developed under isometric 
conditions and power developed in the CMJ and SPJ, power of legs developed during determination of $F-v$ characteristics and punch force developed with lower and upper limbs. The main findings of the present study were that the maximal force developed for an individual Apdolio rear leg kick was significantly higher than the maximum lead leg kicking force. The maximum values of kicking forces developed in a simulated fight were lower than the forces developed in the test of individual kicks. Strong relationships were observed between leg power developed in the SPJ and force of individual Apdolio kicks performed with the lead $(r=0.87)$ and rear leg $(r=0.74)$. In a study by Pędzich et al. [22], WTF taekwondo athletes developed in static conditions the following joint torques for the flexors and extensors of the rear upper limb: elbow joint $-1.1 \pm 0.1$ $\mathrm{N} \cdot \mathrm{m} / \mathrm{kg}, 0.71 \pm 0.1 \mathrm{~N} \cdot \mathrm{m} / \mathrm{kg}$, shoulder joint $-1.48 \pm 0.3$ $\mathrm{N} \cdot \mathrm{m} / \mathrm{kg}, 1.42 \pm 0.3 \mathrm{~N} \cdot \mathrm{m} / \mathrm{kg}$; for the lower limb: knee joint $-2.12 \pm 0.3 \mathrm{~N} \cdot \mathrm{m} / \mathrm{kg}, 3.62 \pm 0.7 \mathrm{~N} \cdot \mathrm{m} / \mathrm{kg}$, hip joint $2.81 \pm 0.4 \mathrm{~N} \cdot \mathrm{m} / \mathrm{kg}, 6.37 \pm 0.7 \mathrm{~N} \cdot \mathrm{m} / \mathrm{kg}$; and for the body trunk $-3.94 \pm 0.6 \mathrm{~N} \cdot \mathrm{m} / \mathrm{kg}, 7.09 \pm 0.4 \mathrm{~N} \cdot \mathrm{m} / \mathrm{kg}$. The values of joint torques in WTF taekwondo athletes were insignificantly lower than the results obtained by the athletes from the study by Pędzich et al. [22]. This is likely to have been caused by the use of different measurement positions and performing the measurements on different test stands. In a study by Cetin et al. [5] taekwondo athletes (age and training experience the same as in this study) performed the akimbo counter movement jump (ACMJ) to the height of $47.18 \mathrm{~cm}$. Our taekwondo athletes jumped higher than taekwondo athletes described by Cetin et al. [5] and similarly to the taekwondo athletes $(0.527 \pm 0.111 \mathrm{~m}) \mathrm{de}-$ scribed by Noorul at al. [21]. No relation was found between punching and kicking forces and power output, and height of CMJ.

There have been no studies in the literature describing determination of the $F-v$ and $P-v$ characteristics in taekwondo athletes. A study by Buśko and Wit [3] described the relationship of $F-v$ in karatekas. Peak power in karate athletes was $11.67 \pm 0.87 \mathrm{~W} / \mathrm{kg}$. In this study, taekwondo athletes developed peak power of $12.25 \pm 1.51 \mathrm{~W} / \mathrm{kg}$, which means a level higher than the values recorded for the karatekas. In a study by Heller et al. [13], taekwondo athletes (age and training experience the same as in this study) developed peak power of $14.7 \mathrm{~W} / \mathrm{kg}$ in the 30 -second Wingate test. Furthermore, in a study by Cetin et al. [5], taekwondo athletes developed peak power of 9.09 $\mathrm{W} / \mathrm{kg}$ in the 30-second Wingate test. In the present study, taekwondo athletes had the power of $11.32 \pm 0.73 \mathrm{~W} / \mathrm{kg}$ for the load of $7.5 \%$ BW. These results were lower than the values presented by Heller et al. [13] and higher than the values documented by Cetin et al. [5].

The force of a punch or a kick delivered to a punching bag is a crucial element of special fitness [4]. Pieter and Pieter [24] used a punching bag filled with water to record the value of kick force in the range from $461.8 \pm 100.7 \mathrm{~N}$ to $661.9 \pm 52.7 \mathrm{~N}$. Falco et al. [15] measured the Bandal Chagui kick force using a punching dummy with piezoelectric pressure sensors. These researchers documented maximal forces of $2089.8 \pm 634.7 \mathrm{~N}$. The highest recorded value of force was $3482 \mathrm{~N}$. Li et al. [19] found forces of about $2940 \mathrm{~N}$ for males in a roundhouse kick. The findings of the study by Buśko et al. [2] using lower limb kicks to an accelerometer punching bag by taekwondo athletes ranged from 1576 to $5315 \mathrm{~N}$ (Apdolio: lead leg $1206.7 \pm 239.5 \mathrm{~N}$, rear leg $2072.3 \pm 472.2 \mathrm{~N}$; and Dwit Chagi: lead leg $3514.6 \pm 1190.4 \mathrm{~N}$, rear leg $3426.1 \pm 911.0 \mathrm{~N}$ ). In a study by Pędzich et al. [23], WTF taekwondo athletes $(n=5)$, who performed Dwit Chagi kicks on a force plate hung on the wall, developed the force of $8569 \pm 2382 \mathrm{~N}$ with the right leg and $7751 \pm 2570 \mathrm{~N}$ with the left leg. In contrast, Sidthilaw [26] used three accelerometers to record peak forces of up to $14024 \mathrm{~N}$ for Thai boxing roundhouse kicks. The impact forces upon delivering kicks were reported at a broad range of 461-14024 $\mathrm{N}$ depending on the adopted measurement methods and types of punches and kicks [10, 23, 24, 26]. In this study, the force of the Apdolio kick with the rear and lead legs and Dwit Chagi was $4580.8 \pm 641.1$ $\mathrm{N}, 3409.5 \pm 581.3 \mathrm{~N}, 3568.0 \pm 1306.0 \mathrm{~N}$, respectively, whereas the force of the straight and hook punches in taekwondo athletes was $1659.2 \pm 254.2 \mathrm{~N}$ and $1843.8 \pm 453.3$ $\mathrm{N}$, respectively. The force of the Dwit Chagi kicks did not differ from the results obtained in a study by Buśko et al. [2]. Furthermore, the force of the Apdolio kicks was nearly three times higher than in the study by Buśko et al. [2]. No studies in the literature have documented the force of punches performed with upper limbs by taekwondo athletes. The available data concern only boxers. The values of punching forces recorded in boxers ranged from 500 to $4800 \mathrm{~N}[15,27]$. Smith et al. [27] found that the value of force of the straight punch performed with the rear limb was $4800 \pm 227 \mathrm{~N}$ in the best boxers, $3722 \pm 133 \mathrm{~N}$ in the medium-class boxers and $2381 \pm 116 \mathrm{~N}$ in beginner boxers, with $2847 \pm 225 \mathrm{~N}, 2283 \pm 126 \mathrm{~N}$ and $1604 \pm 97 \mathrm{~N}$, respectively, for the lead hand. In a study by Karpiłowski et al. [15], maximum values of punching force were 2697 N. Since taekwondo athletes do not use the upper limbs to fight as often as boxers, it seems that the force of their punches should be lower than in boxers. In the present study, values of forces for the upper limb were similar to the results of boxers from the study by Karpiłkowski [15] and Smith et al. [27] for beginner athletes. The results of the study by Buśko et al. [1] suggest that the results obtained in this study using the dynamometric punching bag should be comparable to the results obtained on the accelerometer punching bag used in the study by Buśko et al. [2]. However, the analysis of power punches and/or kicks should take into account the fact that the measured force of the punches depends on the method of measurement, 
technical skills of athletes, the type of punch (straight or hook), the punching limb (lead or rear hand), and the type of boxing gloves used [15, 23, 24, 27].

The study evaluated the relationship between peak torque of the main muscle groups, jumping ability and punching and kicking force for techniques performed by taekwondo athletes on a boxing training simulator. The punching force and Apdolio kicking force were correlated with power developed in the SPJ. No relationships were found between the force of punches/kicks and jumping abilities or power developed in the CMJ. Strong relationships were observed between JT and the force of the straight punch and Apdolio kicks with the exception of JT for the knee joint and trunk. No relationship was found between JT and the force of kicks developed in the 120 -second simulation fight test for both types of kicks. In a study by Karpiłowski et al. [16], the strongest correlations occurred between maximal torques in trunk flexors and the force of a punch with the rear (0.475) and lead (0.571) limb in athletes from the national boxing team. The substantial effect during punching and kicking with the rear limb was from the shoulder flexors $(0.486)$, whereas a small effect was observed for the elbow flexors (0.263) and the flexors $(0.320)$ and extensors $(0.267)$ of the knee joint. The force of punches with the left limb was less strongly correlated with forces of muscles in isometric conditions. The values of the linear correlation coefficients in this study were much higher. This might result from the fact that in the study by Karpiłowski et al. [16], the force of a punch or kick was recorded during a simulated three-minute fight using the boxing training simulator rather than in the test of individual techniques.

\section{Conclusions}

The results obtained in this study lead to the following conclusions:

- the maximal force developed for an individual Apdolio real leg kick was significantly higher than the maximum lead leg kicking force,

- the maximum values of kicking forces developed in a simulated fight were lower than the forces developed in the test of individual kicks,

- maximal joint torques in the lead leg and lead hand measured in static conditions were insignificantly lower than maximal joint torques in the rear leg and rear hand with the exception of the extensors and flexors of the arm joint,

- there is a high correlation between the maximal force of a punch and maximal joint torques; in the case of kicks, a strong relationship was found between the strength of kicks and joint torques for flexion and extension in the hip joint,
- no relationships were observed between the force of punches/kicks and parameters of the $\mathrm{CMJ}$ or power developed during determination of the $F-v$ characteristics.

\section{Practical applications}

Lack of differences in the values of forces between the rear and lead limbs and finding correlations between the punching or kicking force and the joint torques for upper limbs and the torques for the knee flexors and extensors are likely to show that the punching and kicking force may depend on other factors, e.g. technique. The relationship between the power in the SPJ and the Apdolio kick force leads to the practical implication that the test of a vertical jump with an approach run can be used to monitor training adaptations. The results obtained allow for the choice of the appropriate methods and training exercises, e.g. the use of plyometric training or more focus on strength conditioning of the flexors and extensors of the knee joint.

The use of all these methods provides more information for planning of optimal training control.

\section{Conflict of interest: Authors state no conflict of interest.}

\section{References}

1. Buśko K., Staniak Z., Łach P., Mazur-Różycka J., Michalski R., Górski M. (2014) Comparison of two boxing training simulators. Biomed. Hum. Kinet., 6: 135-141. DOI: 10.2478/bhk-2014-0022.

2. Buśko K, Staniak Z, Szark-Eckardt M, Nikolaidis P.T., Mazur-Różycka J., Łach P., Michalski R., Gajewski J., Górski M. (2016) Measuring the force of punches and kicks among combat sport athletes using a modified punching bag with an embedded accelerometer. Acta Bioeng. Biomech., 18(1): 47-54.

3. Buśko K., Wit B. (2002) Force-velocity relationship of lower extremity muscles of karate athletes and rowers. Biol. Sport, 19(4): 373-384.

4. Čepulėnas A., Bružas V., Mockus P., Subacius V. (2011) Impact of physical training mesocycle on athletic and specific fitness of elite boxers. Arch. Budo, 7(1): 33-39.

5. Cetin C., Keçeci A.D., Erdoğan A., Baydar M.L. (2009) Influence of custom-made mouth guards on strength, speed and anaerobic performance of taekwondo athletes. Dent. Traumatol., 25(3): 272-276. DOI: 10.1111/j.16009657.2009.00780.x.

6. Chan K., Pieter W., Moloney K. (2003) Kinathropometric profile of recreational taekwondo athletes. Biol. Sport, 20: $175-179$.

7. Cohen J. (2013) Statistical power analysis for the behavioral sciences. Academic press. 
8. Del Vecchio F.B., Franchini E., Del Vecchio A.H.M. Pieter W. (2011) Energy absorbed by electronic body protectors from kicks in a taekwondo competition. Biol. Sport, 28(1): 75-78.

9. Długołęcka B., Sadowski J., Litwiniuk A., Bujak Z. (2006) Comparison of selected parameters of physical efficiency in fighting sports-on examples of taekwon-do and kick-boxing. Polish J. Sports Med., 22: 35-39.

10. Falco C., Alvarez O., Castillo I., Estevan I., Martos J., Mugarra F., Iradi A. (2009) Influence of the distance in a roundhouse kick's execution time and impact force in Taekwondo. J. Biomech., 42(3): 242-248. DOI: 10.1016/j. jbiomech.2008.10.041.

11. Gajewski J., Buśko K., Mazur J., Michalski R. (2011) Application of allometry for determination of strength profile in young female athletes from different sports. Biol. Sport, 28(4): 239-243.

12. Gajewski J., Michalski R., Buśko K., Mazur-Różycka J., Staniak Z. (2018) Countermovement depth - a variable which clarifies the relationship between the maximum power output and height of a vertical jump. Acta Bioeng. Biomech., 20(1): 127-134. DOI: 10.5277/ABB-010582017-02.

13. Heller J., Peric T., Dlouhá R., Kohlíková E., Melichna J., Nováková H. (1988) Physiological profiles of male and female taekwon-do (ITF) black belts. J. Sports Sci., 16(3): 243-249.

14. Hopkins W.G. (2002) A Scale of Magnitudes for Effect Statistics. A New View of Statistics 2015, Avaliable at: http://www.sportsci.org/resource/stats/effectmag.html.

15. Karpiłowski B., Nosarzewski Z., Staniak Z. (1994) A versatile boxing simulator. Biol. Sport, 11(2): 133-139.

16. Karpiłowski B., Nosarzewski Z., Staniaki Z., Trzaskoma Z. (2001) Dependence between the impact force and the static moment of force of some chosen muscle units in boxing. Acta Bioeng. Biomech., 3(Suppl. 2): 241-244 [in Polish].

17. Koh J.O., Cassidy J.D. (2004) Incidence study of head blows and concussions in competitive taekwondo. Clin. J. Sports Med., 14: 72-79.

18. Lewandowska J., Buśko K., Pastuszak A., Boguszewska K. (2011) Somatotype variables related to muscle torque and power in judoists. J. Hum. Kinet., 30: 21-28. DOI: 10.2478/v10078-011-0069-y.
19. Li Y., Yan F., Zeng Y., Wang G. (2005) Biomechanical analysis on roundhouse kick in taekwondo. In: Proceedings of the 23th International Symposium on Biomechanics in Sports. Beijing, China, 391-394.

20. Markovic G., Vucetic V., Cardinale M. (2008) Heart rate and lactate responses to taekwondo fight in elite women performers. Biol. Sport, 25(2): 135-146.

21. Noorul H.R., Pieter W., Erie Z.Z. (2008) Physical fitness of recreational adolescent taekwondo athletes. Braz. J. Biomot., 2(4): 230-240.

22. Pędzich W., Mastalerz A., Sadowski J. (2012) Estimation of muscle torque in various combat sports. Acta Bioeng. Biomech., 14(4): 107-112.

23. Pędzich W., Mastalerz A., Urbanik C. (2006) The comparison of the dynamics of selected leg strokes in taekwondo WTF. Acta Bioeng. Biomech., 8(1): 83-90.

24. Pieter F., Pieter W. (1995) Speed and force in selected taekwondo techniques. Biol. Sport, 12: 257-266.

25. Said El Ashker S. (2012) Technical performance effectiveness subsequent to complex motor skills training in young boxers. Eur. J. Sport Sci., 12(6): 475-484.

26. Sidthilaw S. (1996) Kinetic and kinematic analysis of Thai boxing roundhouse kicks. Doctoral dissertation, Tese (Doctor of Philosophy) - Human Performance, Oregon State University, Corvallis.

27. Smith M.S., Dyson R.J., Hale T. Janaway L. (2000) Development of a boxing dynamometer and its punch force discrimination efficacy. J. Sports Sci., 18(6): 445-450.

28. Toskovic N.N. (2001) Alterations in selected measures of mood with a single bout of dynamic Taekwondo exercise in college-age students. Percept. Mot. Skills, 92: 1031-1038.

\section{Received 23.01.2018 \\ Accepted 30.05.2018}

(C) University of Physical Education, Warsaw, Poland

Acknowledgments

The study was supported by the Ministry of Science and Higher Education (Grant Institute of Sport No. A.4.1.). 